\title{
Ruy Fausto e a dialetização da dialética
}

\author{
Resenha de $O$ capital e a lógica de Hegel: dialética \\ marxiana, dialética hegeliana, de Ruy Fausto. \\ Traduzido por Arthur Hussne Bernardo, Nicolau \\ Spadoni e Paulo Amaral (São Paulo: Editora Unesp, \\ 2021).
}

\author{
Régis de Melo Alves \\ regisalves@hotmail.com \\ (Universidade de São Paulo, São Paulo, Brasil)
}

DOI: http://dx.doi.org/10.11606/issn.2318-9800.v26i2p149-158

Depois de 24 anos da publicação do original em francês, é publicada este ano a tradução brasileira de Le Capital et la Logique de Hegel: Dialectique marxienne, dialectique hégélienne (1997), livro que Ruy Fausto originalmente concebeu como o terceiro e último tomo de uma série sobre a relação entre as dialéticas hegeliana e marxista na forma de um comentário de $O$ Capital. Esta série complementa e aprofunda um dos eixos de sua outra célebre e influente série, Marx: lógica e política ${ }^{1}$ (1983, 1987 e 2002), em que busca analisar e criticar os fundamentos do marxismo a partir de uma reconstituição rigorosa do sentido da lógica dialética que lhe serve de fundamento. Diferentemente do primeiro e único outro volume publicado desta série, mais restrito à noção de circulação simples no interior dos quatro primeiros capítulos de 0 Capital $^{2}$, aqui o autor tem por objeto tanto o movimento da apresentação e alguns momentos privilegiados do livro I, abordados na primeira parte, como

\footnotetext{
1 Doravante MLP.
}

2 Além da reconstituição da apresentação destes primeiros capítulos à luz de algumas noções centrais da lógica hegeliana - em particular, da doutrina da essência -, no apêndice, a dialética marxiana é confrontada com modelos estruturalistas (Lévi-Strauss) e pré-estruturalistas (Marcel Mauss e Max Weber) de ciência social, tendo por eixo o estatuto da linguagem. Cabe lembrar que Fausto redigiu um tomo intermediário para esta série que, no entanto, decidiu-se por não publicar. 
também a apresentação do conjunto dos três livros de $O$ Capital e alguns de seus momentos centrais, na segunda parte, em particular dos livros I e III. Tendo em vista o parco progresso na compreensão da relação entre a Ciência da Lógica e O Capital - que contribuiu para o progressivo abandono prematuro do marxismo na França nas décadas de 1970 e 1980 -, Fausto primeiro investiga as aproximações e paralelismos entre ambas as obras na primeira parte do livro; depois, na segunda parte, a partir do sexto e, principalmente, do sétimo capítulos, marca as diferenças entre as duas dialéticas ${ }^{3}$, indicando o progresso da dialética marxiana do capital frente à dialética hegeliana da ideia - aquela dialetizaria a própria dialética ao abarcar o elemento não dialético da corruptibilidade do sistema lógico-dialético -, para, por fim, indicar as limitações desta dialetização no âmbito prático, que terão consequências principalmente para o pensamento dialético pós-marxiano sobre história, política e ética ${ }^{4}$.

$\mathrm{Na}$ breve primeira parte, Fausto procura ressaltar os momentos chave do primeiro livro em que podemos encontrar o "hegelianismo" de Marx, que "está, lá onde - porque visível - ele se torna invisível” (Fausto, 2021, p. 23). Em face da abundante terminologia hegeliana deste primeiro livro, que muitas vezes foi desprezada ou má compreendida, coube ao autor assinalar dois lugares que marcam o caráter irredutivelmente dialético de sua apresentação: a seção I, a circulação simples; e a seção VII, que trata da interversão das relações de apropriação. 0 tema da produção capitalista como circulação simples comparece rapidamente por meio de uma longa citação do primeiro tomo de MLP (cf. Fausto, 1983, 181-184) que retoma sua interpretação desta seção, segundo a qual sem as noções hegelianas de posição e pressuposição não se poderia dar conta da contradição dialética de que seu

3 Uma versão abreviada desta segunda parte foi apresentada em um artigo publicado na revista discurso, "Dialética Marxista, Dialética Hegeliana. O Capital e a Lógica de Hegel" (Fausto, 1993), em que a diferença entre ambas as dialéticas é desenvolvida não apenas em vista da relação entre razão e entendimento - termos em que tal diferença é usualmente tratada em MLP (1987) -, mas em torno da ideia de uma dialética limitada e negativa, em que a lógica do ser e da essência ganham relativo privilégio. Aqui apenas esboçamos a hipótese de interpretação do empreendimento faustiano como momento de uma dialetização progressiva da dialética, que acompanha os diferentes momentos históricos, e que, por isso, deve pôr os pressupostos da dialética anterior - e diríamos que de Hegel a Fausto, passando por Marx e Adorno: "Adorno põe - sem humanismo nem naturalismo - o que fica pressuposto em Marx, o gênero humano e a natureza. Essa posição dos pressupostos marxistas corresponde à história do século XX, à exigência que ela coloca, de pôr as determinações que eram apenas pressuposições no século XIX. A transformação que a dialética de Hegel sofre com Marx, no século XIX, é assim a primeira parte de uma história que se prolonga ao século XX com a mutação que a dialética de MarX sofre com os pensadores de Frankfurt. Já no século XXI..." (Fausto, 2021, p. 181).

4 Como afirma Hussne (2020), em MLP Fausto já indicava as limitações históricas da dialética marxiana: "Ao longo dos três livros da série, Ruy não se furta a mostrar quais os objetos escapam ao marxismo: as sociedades totalitárias do leste europeu e da Alemanha nazista; as relações entre homem e natureza; a emergência da guerra atômica; as revoluções nos países do terceiro mundo; os fundamentalismos religiosos". Restava, no entanto, apresentar os limites propriamente lógicodialéticos que se apresentavam em sua filosofia prática à luz da dialética superior presente em seu trabalho teórico de crítica da economia política. 
objeto é e não é o capitalismo. Contudo, a noção de fato central nesta primeira parte é a de interversão [Umschlag], que desenvolve tema já abordado abreviadamente em MLP (cf. idem, 46-54). Ao invés de tratar da interversão no contrário das noções de humanidade e liberdade no capitalismo, no quadro de uma discussão sobre a dialética histórica das formas sociais, agora Fausto demonstra a centralidade lógicodialética da noção de interversão no interior da apresentação do primeiro livro de 0 Capital. Em MLP também encontramos algumas páginas sobre a interversão das leis de propriedade, mas para mostrar como a liberdade contratual da lei da propriedade de mercadorias fundada no trabalho se interverte na não liberdade da apropriação capitalista do trabalho sem equivalente. Ali Fausto visava principalmente a leitura desta passagem para a reprodução global do capital feita pelos althusserianos, Balibar em particular, que corretamente apreende a redução à aparência da lei de propriedade das mercadorias fundada no trabalho, mas que vê nisso somente uma ruptura ou corte com as seções anteriores - somente a descontinuidade, sem apreender a continuidade que revela o aspecto contraditório da interversão das leis da propriedade mercantil que por si próprias levam à apropriação capitalista ${ }^{5}$.

Tudo indica que Fausto pressupõe aqui o viés polêmico subjacente à primeira exposição, já que ainda insiste na interversão como continuidade ${ }^{6}$, mas seu esforço maior é agora o de precisar o estatuto da interversão na reprodução simples e na reprodução ampliada, respectivamente apresentadas nos capítulos 21 e 22 que abrem a seção VII. O problema seria o da justificação da apropriação capitalista por meio de “uma acumulação ainda fundada em um 'trabalho originário’ do capitalista, como pretendem alguns economistas, clássicos ou vulgares” (Fausto, 2021, p. 33). A apropriação capitalista começa a ser posta no interior das seções II a VI como uma primeira negação da propriedade fundada no trabalho próprio. Porém, esta negação não se efetua completamente, pois ainda é possível que os meios de trabalho e o dinheiro para pagar a força de trabalho ainda tenham origem em um trabalho originário do capitalista. Somente com a segunda negação, a interversão da propriedade mercantil em apropriação capitalista, a origem, seja qual for, da acumulação primitiva de capital é deslegitimada. A interversão, entretanto, já pode ser pensada nos limites da reprodução simples, sem que a mais-valia seja reinvestida no processo, já que, por mais que possamos pensar como livre a relação contratual

5 Como afirmava Fausto em MLP (1983, p. 50): "Se for rompida toda continuidade entre os dois momentos, mesmo a continuidade na descontinuidade que caracteriza a Aufhebung, só se apreenderá a apropriação intervertida, não a interversão da apropriação. É finalmente o único resultado a que chega Balibar”. As primeiras seções seriam, assim, recusadas como ilusão humanista e subjetivista. Porém, Marx teria deixado claro que é na continuidade do processo que se daria a interversão e violação da apropriação: "Por mais que o modo capitalista de apropriação pareça violar as leis originais da produção de mercadorias, ele não se origina em absoluto da violação, mas, ao contrário, da observância dessas leis" (Marx, 2013, p. 659).

6 Continuidade no processo que se mostrará imbricada na descontinuidade de sua legitimação (Cf. Fausto, 2021, p. 42, nota 21), como ressalto na sequência. 
entre trabalhador e capitalista no interior da primeira volta completa de reprodução do capital, nas voltas seguintes o contrato não é mais livre, uma vez que a reprodução repõe trabalhador e capitalista como classes antagônicas. Mas é só na reprodução ampliada, com a conversão da mais-valia em capital, que qualquer origem do capital inicial pode ser desconsiderada como legítima. Isto pois o que importa aqui não é simplesmente a liberdade contratual que se interverte em não liberdade, mas porque com o acréscimo progressivo de parcelas de mais-valia reinvestidas no processo produtivo, das quais cada vez mais depende a mais-valia ulterior, o capital inicial restituído a cada ciclo se torna uma quantidade evanescente e virtualmente negligenciável. Assim, as apropriações de mais-valia, posteriores à primeira, têm um efeito retroativo sobre esta de modo que mesmo que a primeira apropriação tenha sido posta como legítima, ela já era também pressuposta como ilegítima, e o desenvolvimento do processo resultaria na posição desta pressuposição.

Cabe notar aqui que a edição brasileira foi acrescida de notas redigidas por Fausto em 2019, em vista da tradução do texto, e que na nota 21 o estatuto da interversão é reapresentado quase que integralmente de forma a dar ver mais claramente o problema de sua diferença no contexto da reprodução simples e ampliada. Esta nota termina com a sugestão de que "o momento da interversão tem alguma coisa a ver com o argumento ontológico" (idem, p. 48). Gostaríamos de destacar a utilidade desta sugestão, já que, assim como no recurso à prova ontológica em alguns pontos de MLP, ela indica um limite à dialética. Tal como na lógica hegeliana a posição integral do conceito subjetivo leva à objetividade por meio do silogismo disjuntivo - passagem que apresentaria o equivalente lógico da tradicional prova ontológica ${ }^{7}$-, também a posição integral do sistema da produção capitalista leva à exterioridade do sistema. Contudo, há uma diferença central aqui. Para Fausto, esta exterioridade do sistema é um além do sistema, o que será afirmado mais à frente, e já nos parece estar sugerido aqui pelo retorno de uma noção da lógica do ser: a medida, que figura como medida exterior em que a própria apresentação da produção capitalista resulta quando emerge uma apropriação sem trabalho que contradiz o funcionamento da própria apresentação até então. Como veremos, esta medida exterior, enquanto exterioridade do próprio sistema e por ele produzida, introduzirá uma abertura à corrupção do sistema capitalista que, diferentemente da ideia hegeliana, pode ser devorado pela contingência e pela finitude.

O objetivo declarado da segunda e maior parte do livro é o de avançar a análise das diferenças entre $O$ Capital e a Ciência da Lógica, principalmente quanto à

\footnotetext{
7 "Ora, do conceito foi inicialmente mostrado que ele se determina até a objetividade. Fica claro por si mesmo que esta última passagem, conforme sua determinação, é o mesmo que, de outra maneira, ocorria na metafísica como o silogismo do conceito, precisamente do conceito de Deus, [em direção] ao seu ser-aí [Dasein], ou seja, como a assim chamada prova ontológica do ser-aí de Deus" (Hegel, 2018, p. 179).
} 
relação entre entendimento e razão, à diversidade particular dos três livros da lógica hegeliana e ao objeto de 0 Capital, que por vezes corre o perigo de ser soterrado pela epistemologia. Porém, o primeiro movimento aqui é ainda o de aproximação com Hegel. O problema que organizará a primeira metade dos dez capítulos desta parte, à luz ainda da proximidade com a dialética hegeliana, é: qual é o correlato objetivo da apresentação de $O$ Capital? Tal problema previne a discussão exclusiva sobre a apresentação do objeto e a consequente redução da dialética marxiana à mera metodologia epistemológica. 0 objeto correlato à apresentação deve ser um movimento, a fim de evitar tanto o empirismo positivista como o racionalismo não-dialético ou estruturalista. 0 objeto não é propriamente uma estrutura, mas, tomando de empréstimo um termo hegeliano, o objeto é a pulsação do sistema enquanto todo imóvel que se interioriza e exterioriza.

Há dois polos nodais nesse duplo movimento de interiorização e exteriorização: o momento da interversão, que representa o ponto de chegada da dialética interiorizante, e o momento de exteriorização das formas, para o qual converge a dialética exteriorizante. No primeiro, o objeto se revela com um máximo de fluidez. As formas se diluem no processo. No segundo, há um máximo de cristalização. Os fluxos se precipitam em formas coisais. Esse movimento desde a fluidez até a cristalização, que deve ser pensado como comportando, objetivamente, um retorno desde a cristalização até a fluidez, é no interior da dialética de Marx, e da produção capitalista, o que chamei (com Hegel) de "pulsação" (idem, p. 63-64).

Nos capítulos seguintes, Fausto apresenta as dialéticas interiorizante e exteriorizante que constituem o movimento "imóvel” de pulsação entre fluidez e cristalização ${ }^{8}$ como preâmbulo para a apresentação do movimento “móvel”, que encetará as diferenças cruciais entre as dialéticas marxiana e hegeliana, discutidas nos capítulos 6, 7 e 8 .

A dialética interiorizante compreende basicamente o movimento geral do livro I, e é pensada a partir de três momentos estruturais: a circulação simples (seção I); a produção capitalista, ou capital enquanto capital (seção II); e a interversão das leis de propriedade, na passagem à reprodução do capital (seção VII). Não será possível entrar nos detalhes de todos os paralelismos com a lógica hegeliana, mas, em linhas gerais, o autor recupera o esquema de negações e posições e pressuposições, apresentados na primeira parte, no qual o fundamento substancial é primeiramente posto, depois negado e tornado base [Grundlage], para então ser restabelecido, mas como fundamento negado. Assim, tais momentos corresponderiam à lógica hegeliana da essência: posição do fundamento do capital (valor e trabalho abstrato) enquanto

8 Fluidez e cristalização, dualidade que remeteria àquela entre fetichismo e convencionalismo, assim como entre economia clássica e pré-clássica, polos que corresponderiam à pulsação entre superstição e Aufklärung, que se criticariam objetivamente no interior do sistema, respectivamente na reprodução e no capital a juro e na propriedade fundiária. Hegel também procurou conciliar superstição e Aufklärung, mas só para Marx tal dialética engendraria uma irracionalidade crescente e ameaçadora à totalidade. 
reflexão; primeira negação do fundamento que dá lugar ao fenômeno [Erscheinung] do capital (mercadoria e dinheiro como suas formas fenomenais); e fundamento reposto, duplamente negado, enquanto aparência [Schein] (circulação simples tornada aparência). Vale notar que a sequência, reflexão, fenômeno e aparência - a dialética interiorizante do fundamento enquanto substância em direção ao fundamento-sujeito, como movimento correspondente também à passagem da essência ao conceito na lógica hegeliana - não segue a ordem de tais conceitos na Doutrina da essência ${ }^{9}$ e, por isso, produz a impressão de uma correspondência um pouco forçada em vista do argumento geral da diferença entre as dialéticas, que encontraremos marcadamente no movimento móvel mais à frente. Também parecem forçadas as correspondências seguintes, que o autor se viu obrigado a fazer, entre momentos da dialética interiorizante e as lógicas do ser e do conceito. Mais interessante é a aproximação desta dialética com o movimento de posição da historicidade do capitalismo, cujas determinações existem de modo exterior a ele, como pré-constituídas na circulação simples, existem como plenamente determinadas no interior da produção capitalista, e no momento da interversão o que é posto é a exterioridade do sistema, que assim corresponde a uma posição da história em geral como história da exploração, possibilitando assim que possa surgir uma outra história geral como pano de fundo para a história da exploração como pré-história.

Já a dialética exteriorizante compreenderia um salto do livro I para o livro III, onde o segundo momento da interiorizante, a posição do capital como sujeito "ao lado" de suas formas fenomenais, serviria de ponto de partida que nos conduziria ao terceiro e último momento da doutrina da essência, a efetividade [Wirklichkeit]. Assim, seus três momentos estruturais se localizariam no livro III: o fundamentosujeito posto como efetividade, e não mais como fenômeno, no preço de produção e no lucro-médio (seções I e II); o capital a juro como forma exteriorizada do fundamentosujeito (seção V); e a renda da terra como forma exteriorizada do fundamentosujeito (seção VII). Ao passo que na interiorizante ocorria uma passagem da substância (trabalho) ao sujeito (capital), caracterizada pela fluidificação máxima da

\footnotetext{
9 Aparência e reflexão são momentos que se seguem no interior do primeiro capítulo (A aparência) da primeira seção (A essência como reflexão dentro dela mesma) da Doutrina da essência. 0 fenômeno figura como segundo capítulo da segunda seção homônima do mesmo livro. Tudo indica que, ao falar do fundamento como base [Grundlage] das formas fenomenais, Fausto tenha visado a relação entre mundo fenomênico e mundo que é em si [Die erscheinende und die an sich seiende Welt] - que medeia o capítulo do fenômeno-, na qual "a lei é essa identidade simples do fenômeno, por conseguinte, a base, não o fundamento do mesmo (...) como unidade abstrata, ao lado da qual, portanto, também ocorre o outro conteúdo do fenômeno" (Hegel, 2017, p. 162). No entanto, a desproporção dos momentos constituintes da dialética interiorizante parece revelar uma escolha a dedo do paralelo a fim de enfatizar o retorno à aparência do fundamento reposto na interversão e deixar aberto o desenvolvimento do fenômeno em efetividade como ponto de partida da dialética exteriorizante. Tal escolha parece se coadunar com a diferença da dialética marxiana, que conclui com momentos logicamente menos desenvolvidos. Mas a diferença não é explicitada neste momento, que deveria apresentar somente os paralelos.
} 
substância no movimento de reprodução do sujeito-capital, na exteriorizante ocorre um retorno do sujeito à substância, exteriorização do capital nas formas coisificadas e cristalizadas do capital como juro e terra. Haveria aqui uma dificuldade maior no paralelo com a lógica hegeliana, já que os três momentos não se encadeariam na forma de um silogismo, da mesma maneira que era possível fazê-lo com os momentos da dialética interiorizante. O que importa notar é que na dialética exteriorizante “não há volta a um ponto de partida” (idem, p. 83), o juízo que conclui seu silogismo é um momento de irracionalidade, o juízo infinito" ${ }^{10}$ - um não juízo - "o capital é a ... propriedade da terra" (ibidem), exprime uma não relação entre sujeito e predicado, como o "espírito não é vermelho" ou a "rosa não é um elefante".

Tal irracionalidade anuncia uma das diferenças cruciais da dialética marxiana: o de que esta abarca em si o germe da supressão do sistema por ela produzido. Além da correspondência do primeiro momento da dialética exteriorizante com a seção A efetividade da Doutrina da essência, para o autor, o segundo momento, a exteriorização do fundamento como capital a juro, corresponderia à passagem a $A$ ideia, última seção da Doutrina do conceito, uma vez que haveria um retorno do capital à mercadoria análogo ao retorno do conceito à imediatidade do ser na ideia. A passagem do capital a juro para a propriedade e renda fundiária seria análoga à exteriorização da ideia na natureza, momento em que a lógica se encerra passando à esfera da filosofia da natureza. No entanto, haveria uma diferença decisiva em 0 Capital: o momento além da lógica - natureza -, que para Hegel instaura uma nova esfera, ainda reside no interior do sistema, "o capital é a ... propriedade da terra" como irracionalidade última na qual o próprio sistema se interverte. No terceiro momento da dialética exteriorizante não é só a propriedade mercantil que é reposta como aparência, mas é o sistema lógico-dialético como um todo que é apresentado como aparência.

Nos capítulos 6, 7 e 8 desta parte, Fausto desenvolve esta diferença da dialética marxiana. Para tanto, considera também o movimento móvel do sistema, que opera com uma negatividade "vertical", que vai além da negatividade "horizontal" que caracterizava o movimento imóvel da pulsação objetiva do sistema. Esta negatividade evidencia uma "dialética da modalidade" em O Capital que revela a suscetibilidade à corrupção do sistema como um todo. Esta progressão modal é fundamental e de grande interesse por apresentar a especificidade do estatuto sistemático da contingência na crítica da economia política, como ponto de contato entre a dialética sincrônica do capital e a dialética diacrônica das formas sociais. Atravessando toda a obra, tal progressão também é triádica: inicia na circulação simples com a posição do possível ou dos processos normais (possíveis que sim) e a pressuposição da contingência ou

10 "O juízo infinito (...) é (...) um juízo no qual está suprimida [aufgehoben] também a forma do juízo. - Este é, contudo, um juízo absurdo [widersinniges]” (Hegel, 2018, p. 110). 
dos processos anormais (possíveis que não); em seu segundo momento - o conjunto da dialética exteriorizante -, o possível se torna necessário (não possível que não), e o contingente se torna impossível (não possível que sim), oposição entre o necessário e o contingente ainda enquanto normalidade posta e anormalidade pressuposta; no terceiro momento - a seção III dedicada à lei tendencial da queda da taxa de lucro - "a necessidade do sistema se interverte em impossibilidade” (idem, p. 101), e a anormalidade pressuposta é agora posta, assim como a normalidade é pressuposta. Somente com a lei tendencial a contradição global do sistema é posta e, com isso, ele revela sua mobilidade na medida em que sua suscetibilidade à corrupção é posta na tendência, o que não se passaria com a ideia hegeliana, que se exteriorizaria na natureza somente para reencontrar a si mesma no espírito, sem perda ${ }^{11}$.

Assim, os últimos momentos da dialética interiorizante, exteriorizante e da modalidade ultrapassam a lógica hegeliana, já que vão além da lógica do conceito, fazendo retornar uma exterioridade que sugere uma volta para momentos anteriores, à aparência, ao ser, à substância, e mesmo à finitude, que não seriam superáveis no interior do sistema. Podemos dizer que, para Fausto, a dialética marxiana progrediria frente à dialética hegeliana na medida em que não haveria fechamento do sistema na forma da ideia, que serviria como norma a ser reencontrada nas ciências filosóficas reais, em particular no espírito objetivo. Para que a lógica não devenha norma exterior diante das ciências reais do entendimento, este deve interferir na razão dialética, operando paradoxalmente uma função limitadora ${ }^{12}$ e negativa, prevenindo a autonomização da lógica-dialética do sistema enquanto puro sujeito-movimento, uma vez que o terceiro momento não fecha, mas retorna a figuras pré-conceituais: "a dialética de Marx se apresenta como unidade do dialético e do não dialético a serviço da dialética” (idem, p. 175) ${ }^{13}$.

11 Da dialética da modalidade passa-se à teoria da crise em termos de uma dialética do esquecimento e da memória, em que, quando o esquecimento devém abstrato e unilateral - as determinações se fixam em sua diversidade - sobrevém a crise, que é um brusco restabelecimento da memória ou unidade do sistema.

12 A matéria não é absolutamente redutível à razão dialética, e deve permanecer como pressuposto "absoluto", assim como as formas não se separam da matéria, e não podem resguardar uma exterioridade como a lógica diante das ciências filosóficas reais - idealismo objetivo, como o de Hegel, em que as formas engendram o objeto, mas que não é idealismo absoluto, já que não suprime a matéria na ideia. Arriscaríamos dizer que a ênfase de Fausto não é desprovida da consciência da proximidade da matéria, como resto insuperável, não só da coisa em si kantiana, mas também da diferença pós-estruturalista.

13 Fausto parece reformular aqui a identidade especulativa hegeliana - identidade entre identidade e não-identidade - nos termos de uma dialetização da dialética: unidade dialética entre dialética e não dialética. Gostaríamos de indicar o problema de até que ponto a ênfase na dimensão limitadora e negativa do entendimento e da finitude da "mais alta dialética" comportaria, para Fausto, uma finitude da própria contradição e da dialética, como aspectos lógicos de um pensamento "préhistórico" - próprio à história da exploração - ou do pensamento tout court, como para Hegel, já que, neste caso, poderíamos recair mais uma vez no perigo da lógica como norma exterior às ciências reais. 
Por fim, nos últimos dois capítulos, o autor indica as limitações da dialética marxiana. Se a mais alta dialética de O Capital é negativa e limitada enquanto operante no nível teórico, no nível prático, no horizonte da dialética histórica e do projeto político, a tendência é oposta. A apresentação do capital seria um ponto de chegada teórico para além do que adviria uma filosofia prática no plano subjetivo. A impossibilidade do fechamento e da Aufhebung no terceiro momento sairia de cena em vista da posição do comunismo como fim prático pressuposto à apresentação teórica da dialética interna do capitalismo. Fausto por um lado afirma que Marx avança "o conceito negativo de finalidade" (idem, p. 163), herdado de Hegel, já que não é a forma social prévia que é a pressuposição da posterior, mas a morte da forma prévia - assunção da contingência na transição que deveria anular qualquer telos como horizonte pressuposto. Mas, por outro lado, o futuro não seria nem pressuposto para Hegel, sua noção de finalidade seria radicalmente retrospectiva, ao passo que o comunismo para Marx seguiria exclusivamente ao capitalismo - não existiria terceira forma social que não o capitalismo ou comunismo. Do ponto de vista prático, o conceito de finalidade negativa corre o risco de se interverter em finalidade positiva, caso o comunismo seja posto como resultado lógico-dialético do desenvolvimento das formas sociais ${ }^{14}$, risco inerente aos textos de Marx que possibilitou que os mesmos se tornassem fundamento ideológico de uma terceira forma social que de fato existiu: a sociedade burocrática totalitária. Deste modo, da perspectiva do projeto político, Marx teria regredido na dialetização da dialética alcançada em sua crítica da economia política - dialetização, e regressão, que Fausto brilhantemente se empenhou não só em apresentar rigorosamente em seus menores detalhes, mas também em avançar.

14 É verdade que Fausto esboça uma aproximação entre Kant e Marx quanto ao pensamento sobre o futuro histórico a fim de ressaltar a dimensão não dogmática e falibilista do comunismo como telos histórico. Por um lado, para o autor, o futuro histórico e o comunismo em Marx, em seus melhores textos, são apresentados como um saber de ordem reguladora, e não constitutiva - como no marxismo vulgar - de modo similar à antevisão kantiana de futuro (hipótese que teria adiantado em alguns anos àquela do hoje celebrado filósofo japonês Kojin Karatani (2003, p. xi): “Em contraste com o marxismo convencional, Marx recusou-se persistentemente a considerar o comunismo como 'ideia constitutiva (ou uso constitutivo de razão)' no sentido de Kant, e ele raramente falou do futuro (...) Portanto, a dogmatização do comunismo como um 'socialismo científico' foi bem o tipo de metafísica que Marx refutou. Mas isto não é contraditório com o fato de que ele cultivava o comunismo como 'ideia reguladora (uso regulador da razão)'”. Por outro lado, Marx também avançaria uma dimensão não dogmática própria com a ideia de projeto comunista, que por ser um projeto poderia vir a falhar, o que não participaria da noção kantiana de ordem reguladora. No entanto, "a visão kantiana parece hoje bem mais 'razoável' do que a marxiana" (Fausto, 2021, p. 155), já que por mais que não fosse assertórica ou apodítica, a realização do comunismo enquanto projeto ainda tinha uma probabilidade muito alta de realização, aparecendo como "quase constitutiva", no fim das contas. Não fica muito claro o quanto deste "Marx neohegeliano e dogmático" (ibidem) Fausto coloca na conta dos textos ou das leituras posteriores. De todo modo, Fausto parece pôr uma ambiguidade objetiva no pensamento prático marxiano a fim de lançar luz à via não dogmática por meio da comparação com a função crítica da ordem reguladora kantiana, como também pela ênfase na falibilidade do projeto - o que sugere certa influência sartriana como momento crucial para a dialetização da dialética histórica marxiana no século XX. 


\section{Referências}

Fausto, R. (1983). Marx: lógica e política - tomo 1. São Paulo: Brasiliense.

Fausto, R. (1987). Marx, lógica e política - tomo 2. São Paulo: Brasiliense.

Fausto, R. (1993). dialética marxista, dialética hegeliana. O Capital e A Lógica de Hegel. Discurso, 20, 41-76. DOI: https://doi.org/10.11606/issn.2318-8863. discurso.1993.37956

Fausto, R. (1997). Dialética marxista; dialética hegeliana: A produção capitalista como circulação simples. São Paulo: Paz e Terra.

Fausto, R. (1997a). Le Capital et la Logique de Hegel: Dialectique marxienne, dialectique hégélienne. Paris: L'Harmattan.

Fausto, R. (2002). Marx, lógica e política (tomo 3). São Paulo: Editora 34.

Fausto, R. (2021). O capital e a lógica de Hegel: dialética marxiana, dialética hegeliana. Traduzido por Arthur Hussne Bernardo, Nicolau Spadoni e Paulo Amaral. São Paulo: Editora Unesp.

Hegel, G. W. F. (2017). Ciência da Lógica: 2. A Doutrina da Essência. Tradução de Christian G. Iber e Federico Orsini. Petrópolis: Editora Vozes.

Hegel, G. W. F. (2018). Ciência da Lógica: 3. A Doutrina do Conceito. Tradução de Christian G. Iber e Federico Orsini. Petrópolis: Editora Vozes.

Hussne, A. (2020). Breve biografia do amigo Ruy Fausto. Revista Rosa. vol. 1 (horssérie, $2^{a}$ parte). Recuperado de: https://revistarosa.com/1/ruy-fausto. Acesso em: 20 set. 2021.

Karatani, K. (2003). Transcritique: On Kant and Marx. Tradução de Sabu Kohso. Cambridge: MIT Press.

Marx, K. (2013). O capital: crítica da economia política. Livro I: o processo de produção do capital. Tradução de Rubens Enderle. São Paulo: Boitempo.

Esta obra está licenciada com uma Licença Creative Commons Atribuição-NãoComercial- 